\title{
COMBINATION OF METEOROLOGICAL INDICES AND SATELLITE DATA FOR DROUGHT MONITORING IN TWO DIFFERENT ENVIRONMENTS IN IRAN
}

\author{
M. Behifar ${ }^{1}$, A.A.Kakroodi*2, M. Kiavarz ${ }^{2}$, F. Amiraslani ${ }^{3}$ \\ ${ }^{1}$ Dept. of Remote Sensing, Faculty of Geography, University of Tehran, behifar.mh@ut.ac.ir. \\ ${ }^{2}$ Dept. of Remote Sensing, Faculty of Geography, University of Tehran (a.a.kakroodi, kiavarzmajid)@ut.ac.ir. \\ ${ }^{3}$ Dept. of Remote Sensing, Faculty of Geography, University of Tehran, amiraslani@ut.ac.ir.
}

KEY WORDS: Drought, Iran, Remote Sensing, SPI, TRMM.

\begin{abstract}
:
The main problem using meteorological drought indices include inappropriate distribution of meteorological stations. Satellite data have reliable spatial and temporal resolution and provide valuable information used in many different applications. The Standardized precipitation index has several advantages. The SPI is based on rainfall data alone and has a variable time scale and is thus conducive to describing drought conditions for different application.

This study aims to calculate SPI using satellite precipitation data and compare the results with traditional methods. To do this, satellite-based precipitation data were assessed against station data and then the standardized precipitation index was calculated. The results have indicated that satellite-based SPI could illustrate drought spatial characteristic more accurate than station-based index. Also, the standardized property of the SPI index allows comparisons between different locations, which is one of the remote sensing drought indices limitations.
\end{abstract}

\section{INTRODUCTION}

Water is the foundation of almost all ecosystems. Drought is defined as a moisture deficit below expected levels (Wilhite et al. 2006). Drought is defined as a dry spell relative to its local normal condition and therefore occurs over most parts of the world, even in wet and humid regions. Drought is often classified into three types, Meteorological drought, Agricultural drought and Hydrological drought. This classification is based on sectors which affected by the drought events (Dai, 2011). Drought differs from other hazards, affects a large spatial extent, the onset and end of a drought are difficult to determine (National Disaster Management Guidelines, 2010; Mishra et al., 2007).

Drought is an extreme climate event which is repeated recursively and therefore is a normal part of climate variability. So, it is important to monitor it and make appropriate decision in different sectors for adaptation and risk managements.

Several indices have developed for monitoring drought with their advantage and drawbacks. Meteorological and remotely sensed drought indices are two group of drought monitoring indices.

Meteorological indices are accepted in many official reports and published papers (Hayes, 2000; Zhang et al., 2012).

The SPI were used because it has several advantages. The SPI is based on rainfall alone and has a variable time scale and is thus conducive to describing drought conditions for different application. Standardization of the SPI ensures that the frequencies of extreme events at any location and at any time scale are consistent. The SPI thresholds could be used for different location and climate and so, SPI values would be comparable at different regions (Mishra et al., 2007).

One of most important drawbacks of the index is that the climatological indexed SPI is based on station points and so determining the drought spatial extent would be another challenge that need additional decisions.

On the other hand, researchers have developed different remotely sensed drought indices such as VCI, TCI, VTCI, TVDI and so on (Wan et al.,2004; Liu and Kogan, 1996; Sandholt et al., 2002). Due to define drought classes using these indices, appropriate thresholds are also needed. These thresholds are local and depends on study's time scale. Thus, the result of these indices is not comparable in different reigns and times.

In the present study we concentrated on meteorological drought indices using satellite data. As a result of this combination, we would have standardized indices with good spatial distribution. To do this, we calculate SPI index using satellite precipitation data.

\section{MATERIALS AND METHODS}

\subsection{Study Area}

Several research studies have showed that the extreme drought occurred in Iran (Morid et al., 2006; Raziei et al., 2009; Keshavarz et al., 2013).

Many parts of Iran have dry climate with low annual rainfall and thus, drought induced effects on water resources not only lead to environmental impacts but also socioeconomic one. Therefore, determination of the location, severity and duration of droughts affecting the country could help decision makers in taking appropriate measures such as cultivation program or water management. However, one of the most important challenges is to detect drought affected areas.

The study area is located in the south of Iran between $26.49^{\circ} \mathrm{N}$ to $34.03^{\circ} \mathrm{N}$ and $48.27^{\circ} \mathrm{E}$ to $57.63^{\circ} \mathrm{E}$. The study area covers diverse regions such as coastal, mountainous and inland areas. Figure 1 shows the study area and location of synoptic station

\footnotetext{
* Corresponding author
} 
with more than 15-year data record. The study period was selected between 2000 and 2017.

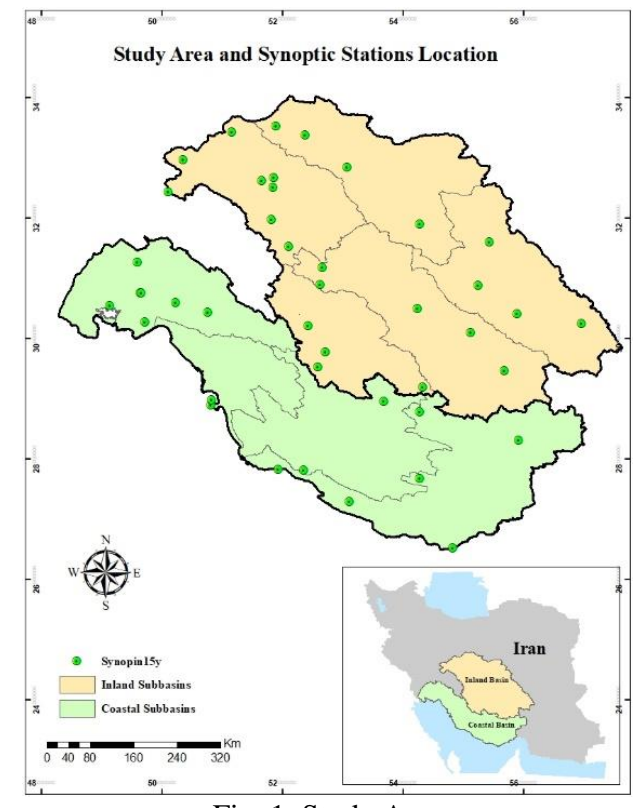

Fig. 1. Study Area

\subsection{Datasets}

\subsubsection{TRMM Data}

TRMM was launched on 27 November 1997. It orbits at an altitude of around $400 \mathrm{~km}$ with an orbital period of around 92.5 minutes, completing approximately sixteen orbits each day. TRMM provides a variety of products. The product used in this paper is 3B43 (Fleming et al., 2011). The TRMM3B43 product algorithm provides the best estimate of the total monthly rainfall from January 1998. Spatially, each record is a $0.25^{\circ} \times 0.25^{\circ}$ grid that covers the globe between latitudes $50^{\circ} \mathrm{N}$ to $50^{\circ} \mathrm{S}$.

Algorithm 3B-43 is executed once per calendar month to produce the single, best-estimate precipitation rate by combining the 3-hourly merged high-quality/IR estimates (3B42) with the monthly accumulated Climate Assessment and Monitoring System (CAMS) or Global Precipitation Climatology Centre (GPCC) rain gauge analysis (3A-45). The 3B-42 estimates are summed for the calendar month, and then the rain gauge data are used to apply a large-scale bias adjustment to the 3B-42 estimates over land. The monthly gauge-adjusted 3B-42 estimate is then combined directly with the rain gauge estimates using inverse error variance weighting (http://disc.sci.gsfc.nasa.gov/data/datapool/TRMM/01_Data_Pr oducts/02_Gridded/index.html).

\subsubsection{Synoptic Station Data}

Seventeen station in different climate region were selected as reference data. The TRMM3B43 data were validated by synoptic station and the SPI indices and drought maps were compared.

\subsection{Methodology}

Nearly 784 pixels of TRMM 3B43 product cover the study area, therefore, the data increase from 17 point to 784 sample.

SPI index was calculated for each pixel of TRMM 3B43. McKee et al., (1993) proposed the standardized precipitation index for drought classification. The SPI is based on precipitation and can be calculated for a variety of timescales.
On short timescales, the SPI is closely related to soil moisture, which is vital for agricultural production, while at longer timescales, the SPI can be related to reservoir storage. The SPI computation has four main steps (Mishra et al., 2007):

1- The determination of probability density function of data

2- Selection of appropriate timescale

3- Computation of the cumulative probability of an observed precipitation

4- Application of the inverse normal_Gaussian_function to the cumulative probability distribution function

In the present study, we used 3, 6 and 12-month timescale (SPI 3 , SPI 6 and SPI 12), and a gamma distribution based on Bazrafshan, 1381.

\section{RESULT}

\subsection{Accuracy assessment of precipitation product}

The accuracy of precipitation estimation was validated using RMSE, MAE and Correlation. The results showed that the total RMSE and MAE of TRMM3B43 over study area were 16.58 and $8.84(\mathrm{~mm} / \mathrm{month})$ respectively. The correlation coefficient between precipitation product and rain gauges was 0.88 . Kohrang station had highest error value. This station located on high mountain and has high amount of precipitation mostly in the form of snow. Generally, the correlation coefficient is quiet well, and make TRMM 3B43 as a proper alternative of rain gauges. Figure 2 shows the Correlation of different stations.

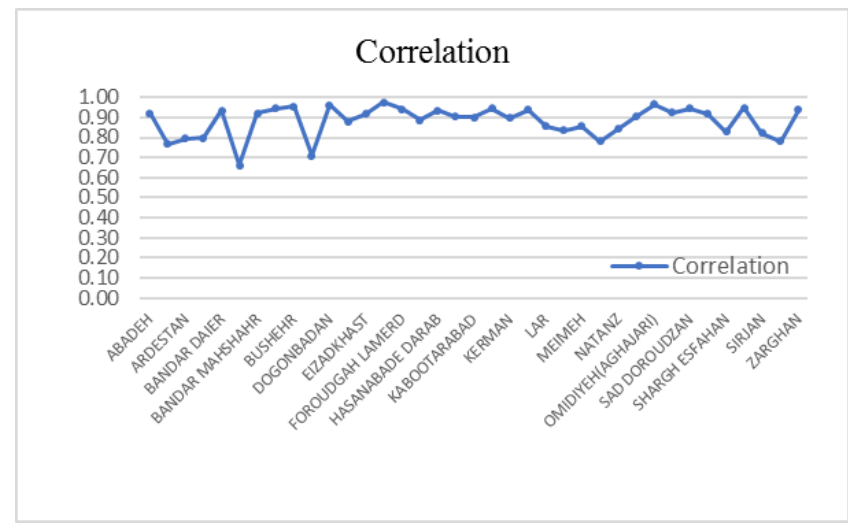

Figure 2. Correlation of precipitation product and rain gauges.

\subsection{Calculation of Drought Index}

As the figure 3 Shows, the SPI values of shiraz station reveal that the study area experienced severe drought in the years 2011, 2008, 2007, 2003 and so on. 


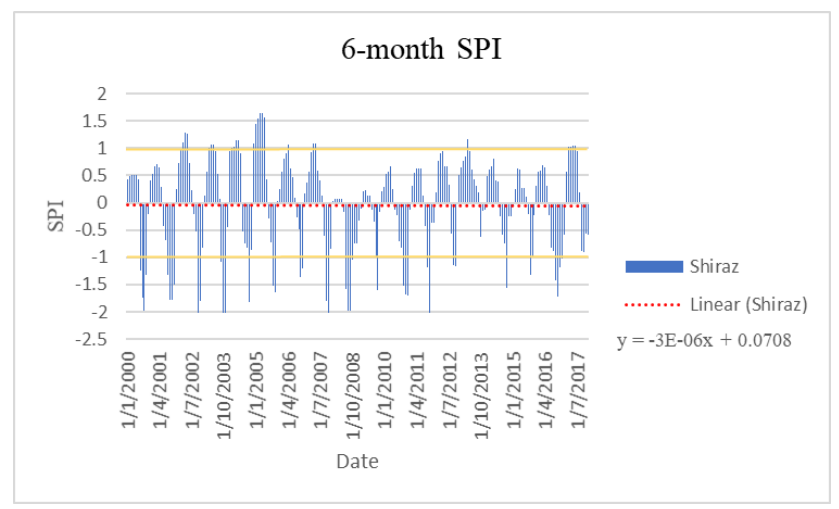

Figure 3. SPI Value of Shiraz Station.

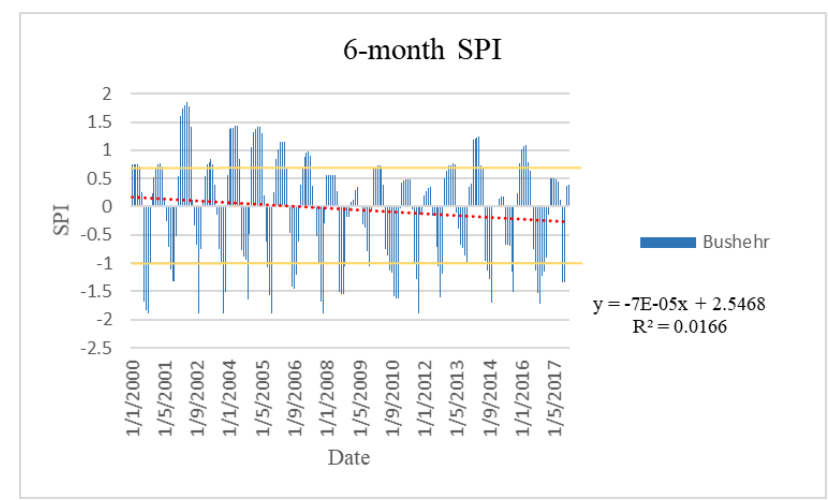

Figure 4. SPI Value of Bushehr Station.

The SPI values of Bushehr station in figure 4, reveal that the study area experienced moderate drought in the years 2014, 2012, 2008 and so on.

These figures illustrate that at the same period of time inland basins have faced more severe drought than coastal basins and also drought intensity were higher for inland basins.

Figure 5 illustrates SPI classes derived from TRMM data. This map shows 6-month SPI index for August 2008. Spatial transition of drought classes is presented. It is obvious that there are some drought classes in the study area without representative ground station.

Figure 6 shows 6-month SPI index for October 2000 derived from TRMM data. The same result can be achieved from the map. There are some drought classes without representative ground station and drought complex spatial patterns can't be gathered with point samples.

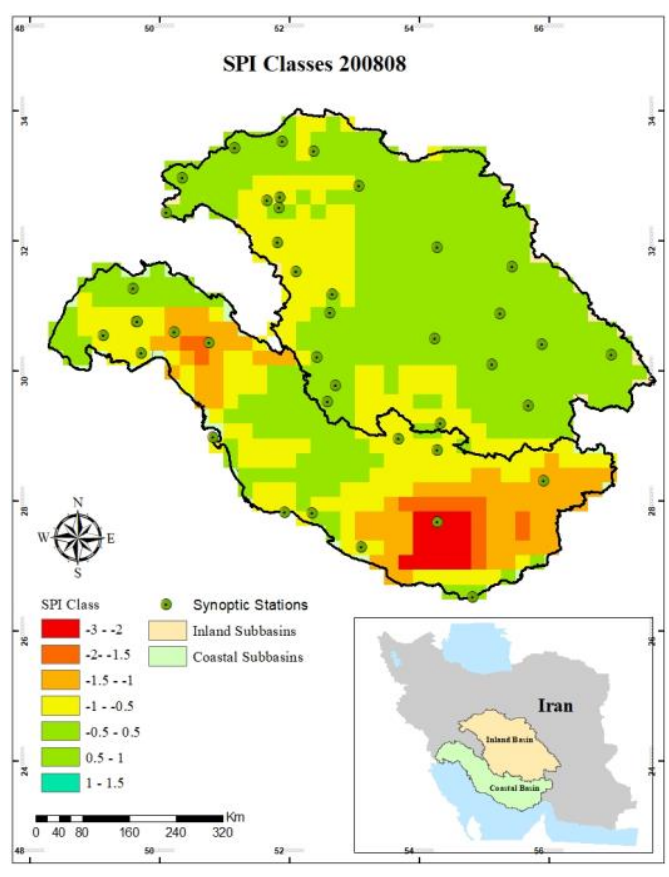

Figure5. SPI Value calculated from TRMM3B43 (200808).

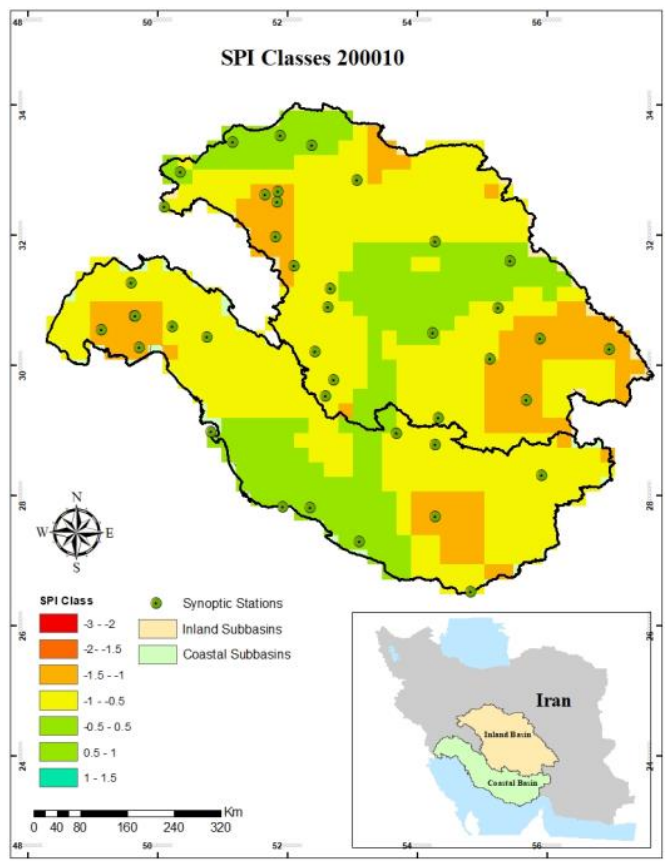

Figure6. SPI Value calculated from TRMM3B43 (200010).

\section{CONCLUSION}

In the present study we calculated SPI index using satellite precipitation data. The result has showed that TRMM3B43 data is capable for calculating meteorological drought indices.

The major limitation of this data is their short period of data. But yet, it is applicable for short term drought monitoring. Also, the SPI values calculated using synoptic stations reveals that the study area experienced several severe droughts in the recent decade. 


\section{REFERENCES}

Dai, A. (2011). Drought under global warming: a review. Wiley Interdisciplinary Reviews: Climate Change, 2(1), 45-65.

Fleming, K., Awange, J., Kuhn, M., \& Featherstone, W. (2011). Evaluating the TRMM 3B43 monthly precipitation product using gridded rain-gauge data over Australia. Australian meteorological and oceanographic Journal, 61.

Hayes, M. J. (2000). Revisiting the SPI: clarifying the process.

Keshavarz, M., Karami, E., \& Vanclay, F. (2013). The social experience of drought in rural Iran. Land Use Policy, 30(1), 120-129.

Liu, W. T., \& Kogan, F. N. (1996). Monitoring regional drought using the vegetation condition index. International Journal of Remote Sensing, 17(14), 2761-2782.

Mishra, A. K., Desai, V. R., \& Singh, V. P. (2007). Drought forecasting using a hybrid stochastic and neural network model. Journal of Hydrologic Engineering, 12(6), 626-638.

Morid, S., Smakhtin, V., \& Moghaddasi, M. (2006). Comparison of seven meteorological indices for drought monitoring in Iran. International Journal of Climatology: A Journal of the Royal Meteorological Society, 26(7), 971-985.

National Disaster Management Guidelines: Management of Drought. A publication of the National Disaster Management Authority, Government of India. ISBN 978-93-80440-08-8, September 2010, New Delhi.

Raziei, T., Saghafian, B., Paulo, A. A., Pereira, L. S., \& Bordi, I. (2009). Spatial patterns and temporal variability of drought in western Iran. Water Resources Management, 23(3), 439.

Sandholt, I., Rasmussen, K., \& Andersen, J. (2002). A simple interpretation of the surface temperature/vegetation index space for assessment of surface moisture status. Remote Sensing of environment, 79(2-3), 213-224.

Wan, Z., Wang, P., \& Li, X. (2004). Using MODIS land surface temperature and normalized difference vegetation index products for monitoring drought in the southern Great Plains, USA. International journal of remote sensing, 25(1), 61-72.

Wilhite, D.A.; Svoboda, M.D.; Hayes, M.J. (2006). Understanding the complex impacts of drought: a key to enhancing drought mitigation and preparedness. Water Resources Management, 21: 763-774.

Zhang, Q., Li, J., Singh, V. P., \& Bai, Y. (2012). SPI-based evaluation of drought events in Xinjiang, China. Natural Hazards, 64(1), 481-492.

GRASS Development Team, 2015. Geographic Resources Analysis Support System (GRASS) Software, Version 6.4. Open Source Geospatial Foundation. grass.osgeo.org (1 June 2017).

GRASS Development Team, 2017. Geographic Resources Analysis Support System (GRASS) Software. Open Source Geospatial Foundation. grass.osgeo.org (20 September 2017).
Lennert, M. and GRASS Development Team, 2017. Addon i.segment.stats. Geographic Resources Analysis Support System (GRASS) Software, Version 7.2, Open Source Geospatial Foundation. grass.osgeo.org/grass7/manuals/addons/i.segm ent.stats (1 June 2017).

Maas, A., Rottensteiner, F., Heipke, C., 2017. Classification under label noise using outdated maps. ISPRS Ann. Photogramm. Remote Sens. Spatial Inf. Sci., IV-1/W1, 215-222. doi.org/10.5194/isprs-annals-IV-1-W1-215-2017.

Smith, J., 1987a. Close range photogrammetry for analyzing distressed trees. Photogrammetria, 42(1), 47-56.

Smith, J., 1987b. Economic printing of color orthophotos. Report KRL-01234, Kennedy Research Laboratories, Arlington, VA, USA.

Smith, J., 1989. Space Data from Earth Sciences. Elsevier, Amsterdam, 321-332.

Smith, J., 2000. Remote sensing to predict volcano outbursts. Int. Arch. Photogramm. Remote Sens. Spatial Inf. Sci., XXVIIB1, 456-469. 